\title{
The Genetics of Prey Susceptibility to
} Myxobacterial Predation: A Review, Including an Investigation into Pseudomonas aeruginosa Mutations Affecting Predation by Myxococcus xanthus

\author{
Natashia Sydney ${ }^{a}$ Martin T. Swain ${ }^{a}$ Jeffery M.T. So ${ }^{b}$ Egbert Hoiczyk ${ }^{b}$ \\ Nicholas P. Tucker ${ }^{c}$ David E. Whitworth ${ }^{a}$ \\ anstitute of Biological, Environmental and Rural Sciences, Aberystwyth University, Aberystwyth, UK; ${ }^{b}$ Department \\ of Molecular Biology and Biotechnology, University of Sheffield, Sheffield, UK; 'Strathclyde Institute of Pharmacy \\ and Biomedical Sciences, University of Strathclyde, Glasgow, UK
}

\section{Keywords}

Myxobacteria $\cdot$ Transposon mutant library $\cdot 96-$ Well plate assays · Clusters of orthologous groups

\begin{abstract}
Bacterial predation is a ubiquitous and fundamental biological process, which influences the community composition of microbial ecosystems. Among the best characterised bacterial predators are the myxobacteria, which include the model organism Myxococcus xanthus. Predation by M. xanthus involves the secretion of antibiotic metabolites and hydrolytic enzymes, which results in the lysis of prey organisms and release of prey nutrients into the extracellular milieu. Due to the generalist nature of this predatory mechanism, $M$. xanthus has a broad prey range, being able to kill and consume Gram-negative/positive bacteria and fungi. Potential prey organisms have evolved a range of behaviours which protect themselves from attack by predators. In recent years, several investigations have studied the molecular responses of a broad variety of prey organisms to $M$. xanthus predation. It seems that the diverse mechanisms employed by prey be-
\end{abstract}

long to a much smaller number of general "predation resistance" strategies. In this mini-review, we present the current state of knowledge regarding $M$. xanthus predation, and how prey organisms resist predation. As previous molecular studies of prey susceptibility have focussed on individual genes/metabolites, we have also undertaken a genomewide screen for genes of Pseudomonas aeruginosa which contribute to its ability to resist predation. P. aeruginosa is a World Health Organisation priority 1 antibiotic-resistant pathogen. It is metabolically versatile and has an array of pathogenic mechanisms, leading to its prevalence as an opportunistic pathogen. Using a library of nearly 5,500 defined transposon insertion mutants, we screened for "prey genes", which when mutated allowed increased predation by a fluorescent strain of $M$. xanthus. A set of candidate "prey proteins" were identified, which shared common functional roles and whose nature suggested that predation resistance by $P$. aeruginosa requires an effective metal/oxidative stress system, an intact motility system, and mechanisms for detoxifying antimicrobial peptides.

C 2021 The Author(s)

Published by S. Karger AG, Basel karger@karger.com www.karger.com/mip

Karger $\stackrel{\text { ' }}{5}$

BOPEN ACCESS
(C) 2021 The Author(s)

Published by S. Karger AG, Basel

This is an Open Access article licensed under the Creative Commons Attribution-NonCommercial-4.0 International License (CC BY-NC) (http://www.karger.com/Services/OpenAccessLicense), applicable to the online version of the article only. Usage and distribution for commercial purposes requires written permission.
Correspondence to:

David E. Whitworth, dew@aber.ac.uk 


\section{Introduction}

Predation is a fundamental and ubiquitous biological process, shaping the biotic composition of ecosystems. Microbial predation dictates the flow of nutrients between members of the microbial food web, with predators incorporating biomass from members of lower trophic levels [Zhang and Leuders, 2017]. Predators are defined as organisms that can kill and consume other "prey" organisms, and in microbes, predation can be facultative or obligate [Pérez et al., 2016]. Nevertheless, many microbes possess "anti-competitor" mechanisms that kill competing cells (e.g., antibiotic-producing Streptomyces spp.), releasing nutrients for general consumption. Consequently, the line between anti-competitor mechanisms and predatory activity is a fine one, and many organisms traditionally not viewed as predators have subsequently been shown to be true predators [Kumbhar et al., 2014].

Microbial predation has been investigated for more than 75 years, and research into the predatory mechanisms of predators has been reviewed and compiled recently [Pérez et al., 2016; Findlay, 2016; Jurkevitch and Mitchell, 2020; Whitworth et al., 2020]. Some microbial predators are considered specialists, while others are more generalist, with predatory activity being dependent on the availability of particular prey organisms. The two best understood microbial predators are the BALOs (Bdellovibrio and like organisms) and the myxobacteria, which possess very different predatory mechanisms [Pérez et al., 2016].

BALOs are typically endobiotic predators, attaching to the outer membrane of Gram-negative prey bacteria and entering their periplasm to form a bdelloplast. Within the bdelloplast, the contents of the prey cell are consumed and the BALO cell replicates before progeny are released from the lysing bdelloplast [Laloux, 2020]. Due to the requirement for periplasmic invasion and residency, the endobiotic mode of predation requires a Gram-negative prey organism.

In contrast, "public goods" predators exemplified by the myxobacteria, but also including Herpetosiphon spp. and Streptomyces spp., secrete antibiotics and/or lytic enzymes which kill prey organisms from the outside [Pérez et al., 2016]. The undirected nature of such predation is associated with broad prey ranges, with prey including Gram-negative bacteria, Gram-positive bacteria and fungi [Morgan et al., 2010; Livingstone et al., 2018a]. Myxobacteria are widely known to produce large numbers of secondary metabolites, many of which have antibiotic activity [Korp et al., 2016; Findlay, 2016]. This, coupled with their broad prey range, which includes important human pathogens, has stimulated many studies into various aspects of myxobacterial predation [reviewed by Berleman and Kirby 2009; Muñoz-Dorado et al., 2016; Furness et al., 2020; Thiery and Kaimer, 2020].

Myxobacteria secrete diffusible antibiotics, which result in zones of growth inhibition of prey lawns, whether surrounding myxobacterial colonies [Xiao et al., 2011] or around paper disks infused with extracted antibiotics [Schneiker et al., 2007]. However, experiments into the predation of Escherichia coli by the myxobacterium Myxococcus xanthus suggest that the antibiotic responsible for growth inhibition (myxovirescin) does not directly kill prey but rather impedes its growth. This suggests that myxobacteria also secrete non-antibiotic substances, which are responsible for prey killing.

Gram-negative bacteria, such as the myxobacteria, secrete outer membrane vesicles (OMVs), which are pinched off portions of the outer membrane enclosing an aqueous volume derived from contents of the periplasm [Whitworth, 2011]. Both proteins and metabolites can be packaged into OMVs, and purified OMVs are themselves predatory, even those purified from non-predatory bacteria [Kadurugamuwa and Beveridge, 1996; Li et al., 1998]. Myxobacterial OMVs were first characterised by Kahnt et al. [2010] and shortly thereafter shown to be able to kill both E. coli and a Pseudomonas sp. strain [Evans et al., 2012]. Several studies have characterised the contents of OMVs from M. xanthus [Kahnt et al., 2010; Berleman et al., 2014; Whitworth et al., 2015; Zwarycz et al., 2020], finding an abundance of hydrolytic enzymes, proteases and secondary metabolites, consistent with a role in predation. A survey of OMV proteomes from different strains of $M$. xanthus found that despite substantial commonality, there was also considerable variability and individuality in OMV proteome composition even within that single myxobacterial species [Zwarycz et al., 2020].

There are several benefits to predators for secreting hydrolytic enzymes within OMVs rather than directly into the extracellular milieu. The delivery of OMV contents is targetable - OMVs can fuse with specific target membranes, delivering cargo into the prey cytoplasm/ periplasm, or they can be triggered to lyse at the surface of prey cells [Kadurugamuwa and Beveridge, 1996]. However, there is currently little understanding of how cargo proteins are targeted for packaging into OMVs, or how OMVs can be targeted to particular destinations. Enclosing cargo proteins protects them from environmental stresses and allows them to maintain their concentrations and potency at a distance from the producing cell. At the
58

Microb Physiol 2021;31:57-66 DOI: $10.1159 / 000515546$
Sydney/Swain/So/Hoiczyk/Tucker/ Whitworth 
same time, packaging cargo within OMVs reduces their rate of transport away from the producing cell [Whitworth, 2011]. This may appear to be a counter-productive behaviour for predatory cells; however, reducing the migration of predatory secretions away from the producer ensures that prey killing only happens proximal to the predatory cell. Such behaviour may be important in reducing competition from kin and other competitors for the nutrients released by lysing prey in the public commons [Marshall and Whitworth, 2019].

It is believed that the broad prey range of myxobacteria and other "public goods" predators is a consequence of their indiscriminate secretion of a multi-valent cocktail of OMVs, hydrolases and antibiotics. However, while myxobacteria are all able to kill a wide range of prey organisms, individual strains show dramatic differences in their profiles of predatory activity against specific prey [Morgan et al., 2010; Livingstone et al., 2017]. It is thought that the patchy mosaic of predatory activity and prey susceptibility observed is a consequence of individualised differences in the composition of each strains' multi-valent predatory cocktail. Such individuality is observed in the OMV cargo proteins of different strains and also in the genes within their genomes. Pan-genome analysis of M. xanthus, Myxococcus spp. and Corallococcus spp. demonstrates that myxobacterial genomes contain large numbers of accessory genes, which are typically unique to those individual strains [Livingstone et al., 2018b; Zwarycz et al., 2020; Chambers et al., 2020].

The lack of correlation between predatory activity, predator phylogeny and prey susceptibility [Livingstone et al., 2017] suggests that individual strains of predator possess unique complements of predatory metabolites and hydrolases, and that what we deduce about the predatory mechanisms of one strain may not be relevant to another predatory strain, even within the same species. Nevertheless, the genomic and proteomic diversity of predatory strains presents opportunities. For instance, genome-wide association studies have been used to correlate myxobacterial predatory efficiency with the presence/absence of specific genes, allowing the identification of enzymes which assist in effective predation of specific prey [Sutton et al., 2019].

\section{The Genetic Basis of Prey Susceptibility/Resistance to Predatory Attack}

As described above, the effectiveness with which a prey organism is consumed by a predatory microbe is highly strain specific. But it is equally clear that the peculiarities of

Susceptibility of Prey to Myxobacterial Predation the prey organism also have a profound effect on the outcomes of predatory encounters. There is no correlation between predatory activity and prey phylogeny, and closelyrelated prey organisms can be preyed upon with very different efficiencies by the same predator [Livingstone et al., 2017]. In general, the role of the prey in the predator-prey relationship has received less attention than that of the predator; however, there are growing numbers of studies which have investigated prey determinants of susceptibility and/or resistance to myxobacterial predation.

\section{Fungi}

While myxobacteria can effectively prey upon fungi, very few studies have investigated the mechanisms involved. Recently, Li et al. [2019] demonstrated that an outer membrane $\beta$-barrel glucanase (GluM) was able to degrade fungal cell walls and impede infection by plant pathogens. GluM showed specificity towards $\beta-1,6-$ glucans, and fungi lacking such linkages were immune to myxobacterial predation, implying GluM is important in dictating predatory specificity towards fungal prey.

\section{Sinorhizobium meliloti}

$M$. xanthus can attack the Gram-negative rhizobium Sinorhizobium meliloti via two distinct predatory modes. In "frontal attack" colonies expand towards each other and encounter each other as dense populations of cells, while during "wolf-pack attack" small groups of cells operate independently to infiltrate prey populations. The effectiveness of frontal attack has been found to be reduced by $S$. meliloti through the production of the exopolysaccharide galactoglucan EPS II [Pérez et al., 2014]. During frontal attack, the area between S. meliloti and M. xanthus accumulates copper. This induces the predator to express copperresistance mechanisms, while the prey produces the antioxidant melanin. Prey strains incapable of producing melanin were found to be more sensitive to predation, suggesting that copper is used by the predator to induce metal/ oxidative stress in the prey [Contreras-Moreno et al., 2020].

\section{Streptomyces coelicolor}

Recently elevated to the status of a predator in its own right, Streptomyces coelicolor is a model Gram-positive organism for studies into secondary metabolism and sporulation. When colonies of M. xanthus and S. coelicolor expand towards each other, the vegetative hyphae of S. coelicolor are lysed, and it responds by producing an aerial mycelium and synthesising the antibiotic actinorhodin [Pérez et al., 2011]. Thus, S. coelicolor resists predation through two strategies: aerial hyphae undergo 
differentiation into chains of spores, which are typically predation-resistant cell types, and antibiotic production represents a "counter-attack" response to predation.

\section{Bacillus subtilis}

Bacillus subtilis is another model Gram-positive organism for studies on sporulation, and it is perhaps not surprizing that $B$. subtilis is induced to sporulate by myxobacterial predation, forming predation-resistant spores [Müller et al., 2014]. Predatory attack by M. xanthus also prompted $B$. subtilis to produce specialised structures called megastructures to house sporulating cells, which prevented M. xanthus from acquiring nutrients from the prey colony [Müller et al., 2015]. As well as differentiating into predation-resistant forms, B. subtilis also employs a counter-attack mechanism, producing the polyketide antibiotic bacillaene, which protects the colony from predation [Müller et al., 2014].

\section{Escherichia coli}

The model Gram-negative bacterium E. coli is one of the most commonly studied prey organisms killed by myxobacteria. Biofilm formation, particularly production of the curli and cellulose matrix components, has been found to provide $E$. coli with protection from predation by M. xanthus [DePas et al., 2014]. Similarly, in an artificial evolution experiment, Nair et al. [2019] showed that predator-prey co-cultures of $M$. xanthus and E. coli drove adaptive evolution of mucoidy in E. coli, in addition to changes in its outer membrane protease OmpT (both features involved with $E$. coli pathogenesis).

Transcriptome profiling of $E$. coli revealed widespread changes in gene expression when co-incubated with $M$. xanthus, with $40 \%$ of $E$. coli genes being significantly differentially expressed [Livingstone et al., 2018c]. Addition of purified M. xanthus OMVs or culture supernatant also induced expression of hundreds of $E$. coli genes. Genes for LPS synthesis, ribosome function and the electron transport chain/oxidative phosphorylation were particularly and consistently up-regulated during exposure to M. xanthus and/or its secretions, suggesting they are the primary molecular targets of attack [Livingstone et al., 2018c]. Unfortunately, it is not clear whether the genes induced by $E$. coli while under attack from $M$. xanthus actually make a difference to predatory outcomes (e.g., prey longevity or survival) or merely reflect the prey trying (unsuccessfully) to maintain homeostasis.

\section{Bacillus licheniformis}

Gram-positive Bacillus licheniformis is able to resist $M$. xanthus predation by inducing expression of an enzyme catalysing the glycosylation of the antibiotic myxovirescin A [Wang et al., 2019]. Glycosylation of myxovirescin is thought to reduce its affinity for its target protein LspA (signal peptidase II), thereby attenuating its antibiotic activity. Accordingly, transplantation of the yjiC gene encoding the glycosylase was able to make recipient E. coli resistant to predation by $M$. xanthus. In B. licheniformis, predation by $M$. xanthus induced expression of both yjiC and $l s p A$, suggesting a two-pronged response to the presence of myxovirescin [Wang et al., 2019].

\section{Unifying Principles}

The molecular details of the responses of specific prey organisms to $M$. xanthus attack are very different from one another, and yet there are commonalities in the general features of the prey responses. We would broadly divide the observed prey strategies for resisting $M$. xanthus predation into 5 categories:

- Being innately resistant. Some prey organisms are intrinsically resistant to the predator's molecules of attack. For instance, fungi lacking $\beta$-1,6-glucans resist M. xanthus predation.

- Producing specific counter-measures. The prey specifically neutralise harmful molecules produced by the attacker. Examples above include the production of melanin by $S$. meliloti and glycosylation of myxovirescin by $B$. licheniformis.

- Reinforcing the cell exterior. Production of a thickened outer layer can be achieved in several ways, including sporulation (as exemplified by S. coelicolor and B. subtilis), or production of an outer sugary coating (e.g., production of EPS/LPS and mucoidy by E. coli).

- Building external protective structures. Usually a communal response to predation, prey cells cooperate by secreting an engulfing matrix, physically separating themselves from the predators. This category includes formation of megastructures by $B$. subtilis and biofilm formation by E. coli.

- Counter-attacking. By producing its own toxic molecules, the prey pre-emptively disables $M$. xanthus, impeding its predation. Examples of this category include production of actinorhodin by $S$. coelicolor and bacillaene production by $B$. subtilis.

Some prey organisms appear to employ just one of these strategies (or one is sufficient to become resistant), but others use multiple strategies, and it is likely that further strategies for the avoidance of $M$. xanthus predation are yet to be discovered. While some predation resistance
60

Microb Physiol 2021;31:57-66 DOI: $10.1159 / 000515546$
Sydney/Swain/So/Hoiczyk/Tucker/ Whitworth 
strategies are adopted by multiple prey, the molecular mechanisms by which they implement each strategy are very different. The genes responsible for some mechanisms could conceivably be transferred between prey while maintaining their function (for instance, transformation with yjiC or acquisition of the bacillaene biosynthetic gene cluster), but other more complex strategies are less likely to be transferable (e.g., megastructure formation and the ability to sporulate).

At the moment, we cannot predict from their genomes whether any particular combination of prey and myxobacterial predator will demonstrate predation, or whether the prey will manifest any particular survival strategy. Perhaps attempting to acquire such understanding is a fruitless task given the complexity of the phenomena involved; however, it is tempting to try. If we can discover at the genomic level how prey and predator genes interact to manifest observed predator-prey phenotypes, we might be able to elevate our understanding of predation resistance mechanisms from anecdotal to universal - a foundational goal of comparative genomics [Whitworth, 2008].

To date, most studies of prey susceptibility have been descriptive or have investigated individual genes that confer the particularly strong selective advantages during M. xanthus predation. We believe it is desirable to take a holistic approach to screen entire genomes for genes that make a quantifiable contribution to predation resistance. While several experimental approaches to achieve this are widely used, we took advantage of a pre-existing library of defined transposon insertion mutants of Pseudomonas aeruginosa, which includes strains carrying disruptions of nearly 4,600 genes [Liberati et al., 2006].

$P$. aeruginosa is a Gram-negative flagellated rodshaped bacterium that is ubiquitous in the environment and commonly found in soil, in water and on plant and animal tissues. It is a facultative anaerobe capable of respiring nitrate and can grow both planktonically or attached to a surface, forming a biofilm at high cell densities [Sønderholm et al., 2017]. It is also an opportunistic human pathogen, causing infections when the host's normal immune defences are disrupted. With the rise in antibiotic-resistant strains, it has been defined by the World Health Organisation as a highest-priority pathogen.

The large genome of $P$. aeruginosa provides it with metabolic versatility and an array of pathogenic mechanisms. It causes infection of burn wounds, often resulting in invasive infections sepsis and death, while respiratory infection is the leading reason of morbidity in cystic fibrosis patients [Dolan, 2020]. P. aeruginosa PA14 is a clinical isolate obtained originally from a burn patient, which displays pathogenicity in a variety of genetically tractable model hosts and mice [Mahajan-Miklos et al., 2000]. Myxobacteria are generally able to prey upon $P$. aeruginosa [Livingstone et al., 2017], and understanding how myxobacterial predators kill this prey (and how the prey resists predation) might allow the development of predation-inspired therapies for treating $P$. aeruginosa infections [Pérez et al., 2020]. We therefore screened mutants of $P$. aeruginosa strain PA14 for genes which on disruption affected predatory efficiency during predation by M. xanthus.

\section{High-Throughput Screening of Prey Susceptibility Genes}

To identify candidate "prey" genes, we screened a library of $P$. aeruginosa strain PA14 transposon insertion mutants (e.g., mutated "predation resistance" genes) for mutations that affected susceptibility to predation by $M$. xanthus. In a 96-well plate format, defined mutations of strain PA14 were co-incubated with a fluorescent strain of $M$. xanthus expressing mCherry (strain EH715).

\section{Bacterial Strains}

Primers mCherry_F_NdeI (ATTCACATATGGTGAGCAAGGGCGAG) and mCherry_R_EcoRI (TACTATGAATTCCTACTTGTACAGCTCGTCCATGC) were used to amplify mCherry from pMKK227 [Koch et al., 2011]. The product was inserted into pMR3679 under the control of a vanillate-inducible promoter [Ineista et al., 2012], producing pJS007. To obtain strain EH715, around $1 \mu \mathrm{g}$ of $\mathrm{pJS} 007$ was used to transform M. xanthus strain DK1622 [Kaiser, 1979] by electroporation. This strain was maintained in the presence of kanamycin at $100 \mu \mathrm{g} / \mathrm{mL}$. Incubation of EH715 in $50 \mu \mathrm{M}$ vanillate for 18 $\mathrm{h}$ gave suitable induction of red fluorescence.

The library of $P$. aeruginosa strain PA14 transposon insertion mutants used here was the PA14NR Set, described by Liberati et al. [2006]. Most of the mutants contained insertions of MAR2xT7 (a derivative of Himar 1 - a mariner family transposon), while a minority contained TnphoA insertions. The PA14NR Set comprises a total of 5,459 mutants, corresponding to 4,596 predicted strain PA14 genes (77\% of predicted genes).

\section{Predator-Prey Assays in 96-Well Plates}

$M$. xanthus EH715 was grown to late exponential phase in DCY (20 g casitone, 2 g yeast extract, $10 \mathrm{~mL} 1 \mathrm{M}$ 


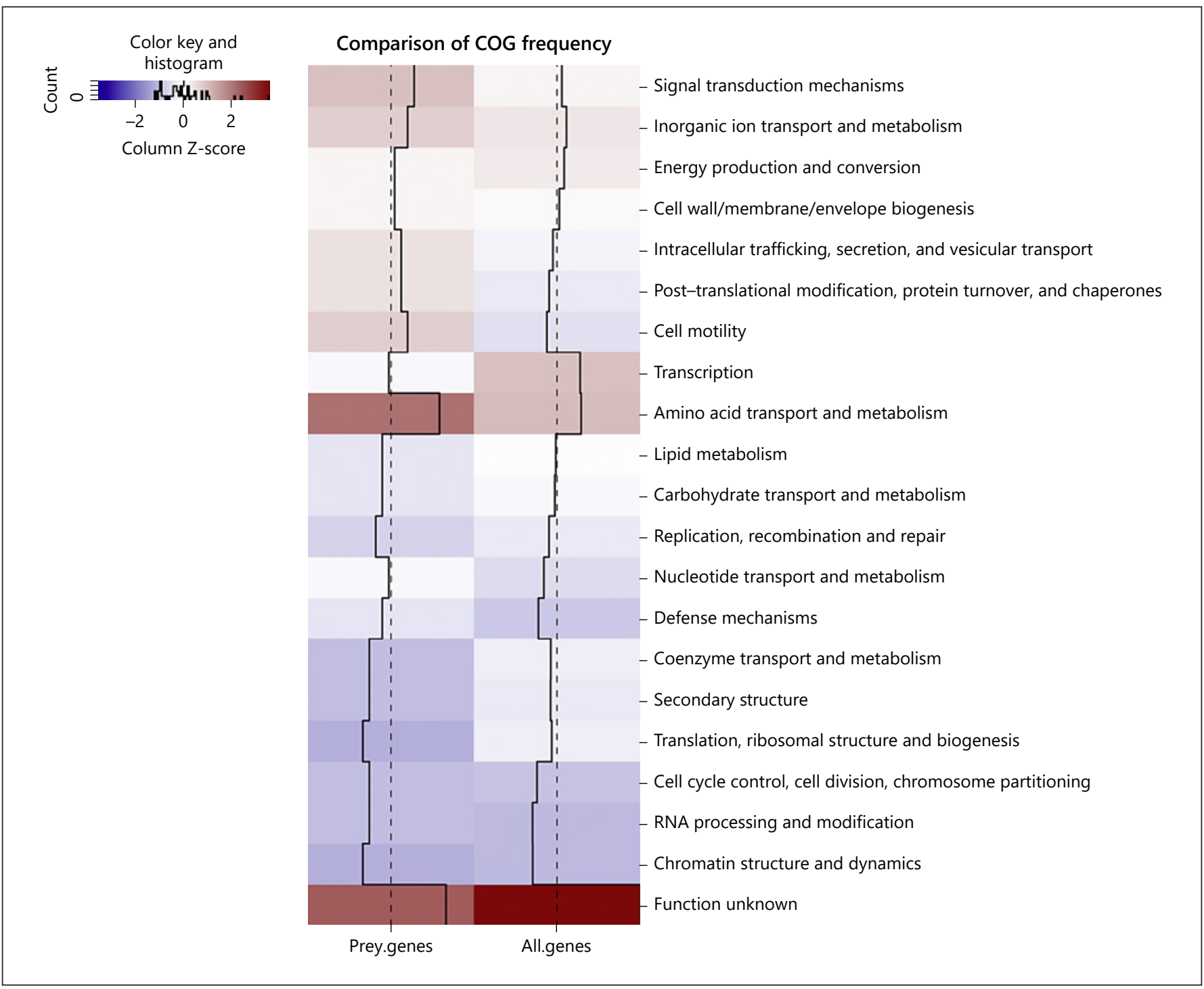

Fig. 1. The relative frequency of COG category membership for "prey genes" (left) and for the total set of genes encoded by the genome (right). Z-scores (deviations from the mean, scaled to zero) are colour coded. Black lines represent normalised frequency values, while the dotted black lines show the average frequency for

Tris $\mathrm{pH} 7.4,8 \mathrm{~mL} 1 \mathrm{M} \mathrm{MgSO}_{4}$ per L) supplemented with $50 \mu \mathrm{M}$ kanamycin and $50 \mu \mathrm{M}$ vanillate. Cells were harvested by centrifugation and resuspended in TM buffer (10 mL $1 \mathrm{M}$ Tris $\mathrm{pH} 7.4,8 \mathrm{~mL} 1 \mathrm{M} \mathrm{MgSO}_{4}$ per L). P. aeruginosa strains were propagated by inoculating into 96well plates containing LB ( $10 \mathrm{~g}$ tryptone, $10 \mathrm{~g} \mathrm{NaCl}, 5 \mathrm{~g}$ yeast extract per $\mathrm{L}$ ) and incubated overnight at $30^{\circ} \mathrm{C}$. Predation assays were set up in singlicate 96-well plates with each well containing an equal volume of $P$. aeruginosa culture and strain EH715 in buffer. Assay plates were in- each gene set. For instance, "amino acid transport and metabolism" genes are relatively frequent within the genome (Z-score $>0$ ), but not as much as within the "prey genes" set. In comparison "cell motility" genes are relatively infrequent in the whole genome (ZScore $<0$ ), but are enriched in the "prey genes" set.

cubated at $30^{\circ} \mathrm{C}$, and $\mathrm{OD}_{600}$ (optical density at $600 \mathrm{~nm}$ ) and fluorescence (excitation at $587 \mathrm{~nm}$, emission at 610 $\mathrm{nm}$ ) were measured after 0 and $24 \mathrm{~h}$. Controls included "cell-free" (just buffer and LB) and "predator-only" wells.

\section{Data Interpretation}

We expected that after a period of incubation, increased susceptibility to predation of strain PA14 mutants by EH715 would be manifested as greater fluorescence compared to controls. This is because the suscep-
Sydney/Swain/So/Hoiczyk/Tucker/ Whitworth 
Table 1. $P$. aeruginosa "prey proteins" with overlapping and/or predation-related functional roles; mutations in the genes encoding these proteins affected predatory growth by M. xanthus in co-culture

\begin{tabular}{|c|c|c|}
\hline Function & Identifier & Description \\
\hline Amino acid metabolism & AspH & Aspartyl/asparaginyl beta-hydroxylase \\
\hline Amino acid metabolism & AstB & $\mathrm{N}$-succinylarginine dihydrolase \\
\hline Amino acid metabolism & Ivd & Isovaleryl-CoA dehydrogenase 1 \\
\hline Amino acid metabolism & $\mathrm{PhzB}$ & Chorismate binding enzyme \\
\hline Amino acid metabolism & PuuA & Glutamine synthetase, catalytic domain \\
\hline Amino acid metabolism & $\operatorname{TrpE}$ & Anthranilate synthase component 1 \\
\hline Chemotaxis & CheA & Chemotaxis protein histidine kinase \\
\hline Chemotaxis & $\mathrm{FliH}$ & Flagellar assembly protein \\
\hline Chemotaxis & FliP & Flagellar biosynthetic protein \\
\hline GGDEF protein & DR97_5,071 & GGDEF diguanylate cyclase domain protein \\
\hline GGDEF protein & $\mathrm{PleD}$ & Response regulator with GGDEF diguanylate cyclase domain \\
\hline Ion transport & FieF & Cation-efflux pump \\
\hline Ion transport & HisJ & Ligated ion channel L-glutamate- and glycine-binding site \\
\hline Ion transport & YocS & Bile acid sodium symporter \\
\hline Ion transport, redox & KefB & Glutathione-regulated potassium-efflux system protein \\
\hline LPS production & ArnT & Transfers L-Ara4N to lipid A \\
\hline LPS production & LptC & Lipopolysaccharide export system protein \\
\hline Protease & ApeB & Aminopeptidase I zinc metalloprotease (M18) \\
\hline Protease & PfpI & DJ-1/PfpI family intracellular protease \\
\hline Protein secretion & BamA & Part of the outer membrane protein assembly complex \\
\hline Protein secretion & FhaC & Member of a two-partner secretion pathway (TPS) \\
\hline Protein secretion & Hcp & Type VI secretion system effector \\
\hline Protein secretion & TadB & Type II secretion system (T2SS), protein F \\
\hline Protein secretion & YscK & YOP proteins translocation protein K (type III secretion) \\
\hline Protein secretion & YscW & Type III secretion system lipoprotein chaperone \\
\hline Quorum quenching & PvdQ & Acyl homoserine lactone acylase \\
\hline Redox processes & Gor & Glutathione reductase \\
\hline Redox processes & GrxD & Glutaredoxin \\
\hline Redox processes & NuoC & $\mathrm{NADH}$-quinone oxidoreductase subunit $\mathrm{C} / \mathrm{D}$ \\
\hline Redox processes & NuoE & Thioredoxin-like $[2 \mathrm{Fe}-2 \mathrm{~S}]$ ferredoxin \\
\hline Transcription factor & ArsR & Helix_turn_helix domain protein, arsenical resistance operon repressor \\
\hline Transcription factor & HexR & Helix-turn-helix domain protein, rpiR family \\
\hline Transcription factor & OhrR & Helix_turn_helix domain protein, multiple antibiotic resistance protein \\
\hline Transcription factor & PilR & Transcription regulatory protein, Fis family \\
\hline Transport & $\mathrm{CcmA}$ & $\mathrm{ABC}$ transporter, $\mathrm{ATP}$-binding protein \\
\hline Transport & DctA & C4-dicarboxylate transport protein \\
\hline Transport & DctQ & Tripartite ATP-independent periplasmic transporter component \\
\hline Transport & OpuCC & Substrate binding domain of ABC-type glycine betaine transport system \\
\hline Transport & $\mathrm{RbsC}$ & Binding-protein-dependent transport system permease family protein \\
\hline Transport & YdhC & Sugar (and other) transporter \\
\hline Transport & YejB & Binding-protein-dependent transport system inner membrane component \\
\hline Transport & YhhJ & $\mathrm{ABC}-2$ family transporter protein \\
\hline
\end{tabular}

tible strain PA14 mutants would be relatively less abundant, while the population of fluorescent strain EH715 would be more abundant, as compared to the controls. As strain PA14 grows much faster than EH715, we also expected that after incubation, a lower $\mathrm{OD}_{600}$ than controls might indicate greater predatory activity. From amongst the 63 plates, 192 mutants were selected which exhibited particularly high fluorescence and/or low opti- cal density measurements. Nucleotide sequences of the mutated genes were translated and annotated with Prokka [Seemann, 2014] and then the annotation was enriched with EggNOG 5.0 [Huerta-Cepas et al., 2019]. This approach yielded 85 candidate "prey proteins," and encouragingly, some of those proteins were identified from multiple plates (AstB, TrpE and YhhJ). The COG (clusters of orthologous groups) categories [Galperin et al., 2019] to 
which "prey proteins" were assigned are indicated in Figure 1. "Prey protein" membership of COG categories was significantly different from that of strain PA14 genomeencoded proteins $\left(\chi^{2}\right.$ test, $\left.p<0.01\right)$.

Individual COG categories enriched (more than 3-fold) among "prey proteins" were A (RNA processing and modification), $\mathrm{N}$ (cell motility), $\mathrm{O}$ (post-translational modification, protein turnover, and chaperones), and $\mathrm{V}$ (defence mechanisms), while COG category J (translation, ribosomal structure and biogenesis) was more than 3 -fold depleted compared to the genome-encoded protein set. As apparent in Figure 1 and as might be expected, prey proteins were generally depleted $(>2$-fold) in the COG super-category "information storage and processing" (which comprises individual COG categories A, B, J, $\mathrm{K}$ and $\mathrm{L}$ ).

\section{Functional Roles of "Prey Proteins"}

Many of the candidate "prey proteins" had overlapping functional roles or common mechanisms, and/or had roles which would be expected to impact on predation resistance (Table 1). For instance, 5 proteins were motility related, including 2 flagella proteins, 2 flagella assembly proteins, and the chemotaxis regulator CheA presumably being able to swim away from predators reduces the impact of predation. Also present in the list of "prey proteins" were several proteins involved in protein secretion systems ( 6 proteins), amino acid metabolism (6 proteins), transport (12 proteins), proteases (2 proteins), and cyclic-di-GMP signalling (2 proteins), which might also hint at general aspects of predator resistance. For instance, cyclic-di-GMP signalling promotes biofilm formation [Güvener and Harwood, 2007].

Other "prey proteins" suggest that $M$. xanthus might attack $P$. aeruginosa with cationic antimicrobial peptides and/or metal/oxidative stress. Five "prey proteins" are involved in processes affecting redox homeostasis, 4 proteins are ion transporters (including a redox-regulated transporter and a cation efflux pump), while a further 4 are transcription factors (including a likely arsenate resistance regulator and a multi-drug resistance regulator). Two prey proteins are involved in LPS (lipopolysaccharide) production, including a glycosyl transferase, which modifies lipid A conferring resistance to cationic antimicrobial peptides and polymyxin. Metal/ oxidative stress is known to mediate myxobacterial predation of S. meliloti [Contreras-Moreno et al., 2020] and many peptides produced by myxobacteria have potent antimicrobial activity [Wenzel and Müller, 2009]. The electron transport chain is a known target of myxo- bacterial predation, and of ubiquitous myxobacterial antibiotics such as the myxalamides [Gerth et al., 1983; Livingstone et al., 2018c].

Also within the list of "prey proteins" was PvdQ, an acylase involved in both siderophore production and acyl homoserine lactone (AHL) degradation in P. aeruginosa. AHLs are widely used bacterial quorum signalling molecules, which promote biofilm formation in Pseudomonas. While biofilm formation is thought to provide protection from predation, $M$. xanthus is able to sense the AHLs produced by prey, stimulating its predatory activity [Lloyd and Whitworth, 2017]. Potentially, PvdQ might increase resistance to predation by preventing AHL-mediated eavesdropping by predators, as well as by stimulating antibiotic resistance [Wang et al., 2011].

It would now be interesting to characterise the "prey proteins" in more detail, ideally using engineered nonpolar mutations. Studies could then be undertaken on those mutants to assess their phenotype, gene expression patterns and the mechanism by which they conferred any selective advantage when subjected to predatory attack.

\section{Conclusion}

The bacterial predator-prey relationship is multi-faceted, seemingly unique to each combination of predator and prey organism. However, it remains likely that identification of specific prey responses to predation will illuminate general features of predation resistance responses. We screened nearly 5,500 mutants of $P$. aeruginosa (covering $77 \%$ of genes in the genome) to identify the genes for proteins conferring resistance to predation by $M$. xanthus. The candidate "prey proteins" identified were enriched for particular COGs and many had overlapping functional roles. The nature of the "prey proteins" identified suggests that effective resistance of predation by $P$. aeruginosa requires systems for resisting metal/oxidative stress and for detoxifying antibiotics and antimicrobial peptides, as well as a functional motility system.

\section{Acknowledgements}

We would like to thank Ainsley Beaton and Charles Begley from the University of Strathclyde for technical assistance with the setting up of the mutant library and Larissa Carvalho Ferreira from Aberystwyth University for assisting with the COG analysis. We would also like to thank the Microbiology Society for organising the conference at which the experiment presented here was first conceived.
Sydney/Swain/So/Hoiczyk/Tucker/ Whitworth 


\section{Conflict of Interest Statement}

There are no conflicts of interest to declare.

\section{Funding Sources}

D.E.W. and M.T.S. received funding for the screening experiment from the Aberystwyth University Research Fund. N.S. is the recipient of an Aberystwyth University President's Scholarship.

\section{Author Contributions}

D.E.W., M.T.S. and N.P.T. devised the project, D.E.W., M.T.S. and N.P.T. supervised the screening experiment, J.S. generated EH715 under the supervision of E.H., N.S. performed the screening experiments and data analysis, all authors edited and approved the final version of the manuscript.

\section{References}

Berleman JE, Kirby JR. Deciphering the hunting strategy of a bacterial wolfpack. FEMS Microbiol Rev. 2009 Sep;33(5):942-57.

Berleman JE, Allen S, Danielewicz MA, Remis JP, Gorur A, Cunha J, et al. The lethal cargo of Myxococcus xanthus outer membrane vesicles. Front Microbiol. 2014 Sep 9;5:474.

Chambers J, Sparks N, Sydney N, Livingstone PG, Cookson AR, Whitworth DE. Comparative genomics and pan-genomics of the Myxococcaceae, including a description of five novel species: Myxococcus eversor sp. nov., Myxococcus llanfairpwllgwyngyllgogerychwyrndrobwllllantysiliogogogochensis sp. nov., Myxococcus vastator sp. nov., Pyxidicoccus caerfyrddinensis sp. nov. and Pyxidicoccus trucidator sp. nov. Genome Biol Evol. 2020 Dec 6;12(12):2289-2302.

Contreras-Moreno FJ, Muñoz-Dorado J, GarcíaTomsig NI, Martínez-Navajas G, Pérez J, Moraleda-Muñoz A. Copper and melanin play a role in Myxococcus xanthus predation on Sinorhizobium meliloti. Front Microbiol. 2020 Feb 4;11:94.

DePas WH, Syed AK, Sifuentes M, Lee JS, Warshaw D, Saggar V, et al. Biofilm formation protects Escherichia coli against killing by Caenorhabditis elegans and Myxococcus xanthus. Appl Environ Microbiol. 2014 Nov; 80(22):7079-87.

Dolan SK. Current knowledge and future directions in developing strategies to combat Pseudomonas aeruginosa infection. J Mol Biol. 2020 Sep 18;432(20):5509-28.

Evans AG, Davey HM, Cookson A, Currinn H, Cooke-Fox G, Stanczyk PJ, et al. Predatory activity of Myxococcus xanthus outer-membrane vesicles and properties of their hydrolase cargo. Microbiology (Reading, Engl). 2012 Nov; 158(Pt 11):2742-52.

Findlay BL. The chemical ecology of predatory soil bacteria. ACS Chem Biol. 2016 Jun 17; 11(6): 1502-10

Furness E, Whitworth DE, Zwarycz A. Predatory interactions between myxobacteria and their prey. In: Jurkevitch E, Mitchell RJ, editors. The ecology of predation at the microscale. Cham, Switzerland: Springer; 2020. p. 1-36.

Galperin MY, Kristensen DM, Makarova KS Wolf YI, Koonin EV. Microbial genome anal- ysis: the COG approach. Brief Bioinform. 2019 Jul 19;20(4):1063-70.

Gerth K, Jansen R, Reifenstahl G, Höfle G, Irschik $\mathrm{H}$, Kunze B, et al. The myxalamids, new antibiotics from Myxococcus xanthus (Myxobacterales). I. Production, physicochemical and biological properties, and mechanism of action. J Antibiot. 1983 Sep; 36(9):1150-6.

Güvener ZT, Harwood CS. Subcellular location characteristics of the Pseudomonas aeruginosa GGDEF protein, WspR, indicate that it produces cyclic-di-GMP in response to growth on surfaces. Mol Microbiol. 2007 Dec; 66(6):1459-73

Huerta-Cepas J, Szklarczyk D, Heller D, Hernández-Plaza A, Forslund SK, Cook H, et al. eggNOG 5.0: a hierarchical, functionally and phylogenetically annotated orthology resource based on 5090 organisms and 2502 viruses. Nucleic Acids Res. 2019 Jan 8;47(D1): D309-14.

Iniesta AA, García-Heras F, Abellón-Ruiz J, Gallego-García A, Elías-Arnanz M. Two systems for conditional gene expression in Myxococcus xanthus inducible by isopropyl- $\beta-D$ thiogalactopyranoside or vanillate. J Bacteriol. 2012 Nov; 194(21):5875-85.

Jurkevitch E, Mitchell RJ, editors. The ecology of predation at the microscale. Cham, Switzerland: Springer; 2020. p. 1-36.

Kadurugamuwa JL, Beveridge TJ. Bacteriolytic effect of membrane vesicles from Pseudomonas aeruginosa on other bacteria including pathogens: conceptually new antibiotics. J Bacteriol. 1996 May;178(10):2767-74.

Kahnt J, Aguiluz K, Koch J, Treuner-Lange A, Konovalova A, Huntley S, et al. Profiling the outer membrane proteome during growth and development of the social bacterium Myxococcus xanthus by selective biotinylation and analyses of outer membrane vesicles. J Proteome Res. 2010 Oct 1;9(10):5197-208.

Kaiser D. Social gliding is correlated with the presence of pili in Myxococcus xanthus. Proc Natl Acad Sci USA. 1979 Nov;76(11):5952-6.

Koch MK, McHugh CA, Hoiczyk E. BacM, an Nterminally processed bactofilin of Myxococcus xanthus, is crucial for proper cell shape. Mol Microbiol. 2011 May;80(4):1031-51.
Korp J, Vela Gurovic MS, Nett M. Antibiotics from predatory bacteria. Beilstein J Org Chem. 2016 Mar 30;12:594-607.

Kumbhar C, Mudliar P, Bhatia L, Kshirsagar A, Watve M. Widespread predatory abilities in the genus Streptomyces. Arch Microbiol. 2014 Apr;196(4):235-48.

Laloux G. Shedding light on the cell biology of the predatory bacterium Bdellovibrio bacteriovorus. Front Microbiol. 2019 Jan 21;10:3136.

Li Z, Clarke AJ, Beveridge TJ. Gram-negative bacteria produce membrane vesicles which are capable of killing other bacteria. J Bacteriol. 1998 Oct;180(20):5478-83.

Li Z, Ye X, Liu M, Xia C, Zhang L, Luo X, et al. A novel outer membrane $\beta$-1,6-glucanase is deployed in the predation of fungi by myxobacteria. ISME J. 2019 Sep;13(9):2223-35.

Liberati NT, Urbach JM, Miyata S, Lee DG, Drenkard E, Wu G, et al. An ordered, nonredundant library of Pseudomonas aeruginosa strain PA14 transposon insertion mutants. Proc Natl Acad Sci USA. 2006 Feb 21;103(8):2833-8.

Livingstone PG, Morphew RM, Whitworth DE. Myxobacteria are able to prey broadly upon clinically-relevant pathogens, exhibiting a prey range which cannot be explained by phylogeny. Front Microbiol. 2017 Aug 22;8:1593.

Livingstone PG, Morphew RM, Cookson AR, Whitworth DE. Genome analysis, metabolic potential, and predatory capabilities of Herpetosiphon llansteffanense sp. nov. Appl Environ Microbiol. 2018a Oct 30;84(22): e01040-18.

Livingstone PG, Morphew RM, Whitworth DE. Genome sequencing and pan-genome analysis of 23 Corallococcus spp. strains reveal unexpected diversity, with particular plasticity of predatory gene sets. Front Microbiol. 2018b Dec 19;9:3187.

Livingstone PG, Millard AD, Swain MT, Whitworth DE. Transcriptional changes when Myxococcus xanthus preys on Escherichia coli suggest myxobacterial predators are constitutively toxic but regulate their feeding. Microb Genom. 2018c Feb;4(2):e000152.

Lloyd DG, Whitworth DE. The myxobacterium Myxococcus xanthus can sense and respond to the quorum signals secreted by potential prey organisms. Front Microbiol. 2017 Mar 14;8:439. 
Mahajan-Miklos S, Rahme LG, Ausubel FM. Elucidating the molecular mechanisms of bacterial virulence using non-mammalian hosts. Mol Microbiol. 2000 Sep;37(5):981-8.

Marshall RC, Whitworth DE. Is "Wolf-Pack" predation by antimicrobial bacteria cooperative? Cell behaviour and predatory mechanisms indicate profound selfishness, even when working alongside kin. Bioessays. 2019 Apr;41(4): e1800247.

Morgan AD, MacLean RC, Hillesland KL, Velicer GJ. Comparative analysis of Myxococcus predation on soil bacteria. Appl Environ Microbiol. 2010 Oct;76(20):6920-7.

Müller S, Strack SN, Hoefler BC, Straight PD, Kearns DB, Kirby JR. Bacillaene and sporulation protect Bacillus subtilis from predation by Myxococcus xanthus. Appl Environ Microbiol. 2014 Sep;80(18):5603-10.

Müller S, Strack SN, Ryan SE, Kearns DB, Kirby JR. Predation by Myxococcus xanthus induces Bacillus subtilis to form spore-filled megastructures. Appl Environ Microbiol. 2015 Jan; 81(1):203-10.

Muñoz-Dorado J, Marcos-Torres FJ, García-Bravo E, Moraleda-Muñoz A, Pérez J. Myxobacteria: moving, killing, feeding, and surviving together. Front Microbiol. 2016 May 26;7: 781.

Nair RR, Vasse M, Wielgoss S, Sun L, Yu YN, Velicer GJ. Bacterial predator-prey coevolution accelerates genome evolution and selects on virulence-associated prey defences. Nat Commun. 2019 Sep 20;10(1):4301.

Pérez J, Muñoz-Dorado J, Braña AF, Shimkets LJ, Sevillano L, Santamaría RI. Myxococcus xanthus induces actinorhodin overproduction and aerial mycelium formation by Streptomyces coelicolor. Microb Biotechnol. 2011 Mar; 4(2):175-83.
Pérez J, Jiménez-Zurdo JI, Martínez-Abarca F, Millán V, Shimkets LJ, Muñoz-Dorado J. Rhizobial galactoglucan determines the predatory pattern of Myxococcus xanthus and protects Sinorhizobium meliloti from predation. Environ Microbiol. 2014 Jul;16(7):2341-50.

Pérez J, Moraleda-Muñoz A, Marcos-Torres FJ, Muñoz-Dorado J. Bacterial predation: 75 years and counting!. Environ Microbiol. 2016 Mar;18(3):766-79.

Pérez J, Contreras-Moreno FJ, Marcos-Torres FJ, Moraleda-Muñoz A, Muñoz-Dorado J. The antibiotic crisis: How bacterial predators can help. Comput Struct Biotechnol J. 2020 Sep 15;18:2547-55

Schneiker S, Perlova O, Kaiser O, Gerth K, Alici A, Altmeyer MO, et al. Complete genome sequence of the myxobacterium Sorangium cellulosum. Nat Biotechnol. 2007 Nov;25(11): 1281-9.

Seemann T. Prokka: rapid prokaryotic genome annotation. Bioinformatics. $2014 \mathrm{Jul} \mathrm{15}$ 30(14):2068-9.

Sønderholm M, Kragh KN, Koren K, Jakobsen TH, Darch SE, Alhede M, et al. Pseudomonas aeruginosa aggregate formation in an alginate bead model system exhibits In vivo-like characteristics. Appl Environ Microbiol. 2017 Apr 17;83(9):e00113-17.

Sutton D, Livingstone PG, Furness E, Swain MT, Whitworth DE. Genome-wide identification of myxobacterial predation genes and demonstration of formaldehyde secretion as a potentially predation-resistant trait of Pseudomonas aeruginosa. Front Microbiol. 2019 Nov 13;10:2650.

Thiery S, Kaimer C. The predation strategy of Myxococcus xanthus. Front Microbiol. 2020 Jan 14;11:2.
Wang L, Zhang C, Gong F, Li H, Xie X, Xia C, et al. Influence of Pseudomonas aeruginosa pvdQ gene on altering antibiotic susceptibility under swarming conditions. Curr Microbiol. 2011 Oct;63(4):377-86.

Wang C, Liu X, Zhang P, Wang Y, Li Z, Li X, et al. Bacillus licheniformis escapes from Myxococcus xanthus predation by deactivating myxovirescin A through enzymatic glucosylation. Environ Microbiol. 2019 Dec;21(12): 4755-72.

Wenzel SC, Müller R. The biosynthetic potential of myxobacteria and their impact in drug discovery. Curr Opin Drug Discov Devel. 2009 Mar;12(2):220-30.

Whitworth DE. Genomes and knowledge - a questionable relationship?. Trends Microbiol. 2008 Nov; 16(11):512-9.

Whitworth DE. Myxobacterial vesicles death at a distance?. Adv Appl Microbiol. 2011;75:1-31.

Whitworth DE, Slade SE, Mironas A. Composition of distinct sub-proteomes in Myxococcus xanthus: metabolic cost and amino acid availability. Amino Acids. 2015 Dec;47(12):252131.

Whitworth DE, Jurkevitch E, Pérez J, Fuhrmann G, Koval SF. Editorial: Mechanisms of prokaryotic predation. Front Microbiol. 2020 Sep 8;11:2071.

Xiao Y, Wei X, Ebright R, Wall D. Antibiotic production by myxobacteria plays a role in predation. J Bacteriol. 2011 Sep;193(18):462633.

Zhang L, Lueders T. Micropredator niche differentiation between bulk soil and rhizosphere of an agricultural soil depends on bacterial prey. FEMS Microbiol Ecol. 2017 Sep 1;93(9).

Zwarycz AS, Livingstone PG, Whitworth DE Within-species variation in OMV cargo proteins: the Myxococcus xanthus OMV panproteome. Mol Omics. 2020 Aug 1;16(4):38797. 